\title{
High-frequency percussive ventilation in acute respiratory distress syndrome: knocking at the door but can it be let in?
}

\author{
Herbert Spapen ${ }^{1 *}$, Jouke De Regt ${ }^{1}$, Viola van Gorp ${ }^{1}$ and Patrick M. Honoré2
}

See related research by Godet et al., https://ccforum.biomedcentral.com/articles/10.1186/s13054-017-1924-6

High-frequency ventilation has been proposed as an alternative ventilation mode for acute respiratory distress syndrome (ARDS). Most experience was gained with high-frequency oscillation but this technique became abandoned due to unwarranted side effects (higher need for sedation and neuromuscular blockade, prolonged hemodynamic instability) and a higher mortality [1].

Godet et al. [2] recently documented the effects of short-term application of high-frequency percussive ventilation (HFPV) in animals and patients with early nonfocal moderate to severe ARDS. HFPV highly improved oxygenation and hemodynamics. In addition, HFPV allowed significant alveolar recruitment without concomitant hyperinflation of aerated lung regions [2]. Based on their observations, the authors suggested further investigation of HFPV on patient outcome during ARDS.

We have published the largest observational study to date on clinical use of HFPV in ARDS [3]. We retrospectively analyzed data from 42 patients (20 pneumoniainduced cases and 22 pneumonia-unrelated cases) with moderate to severe ARDS. HFPV was governed according to a predefined protocol and continued until patients could be switched to conventional ventilation. Essentially, our results corroborate the findings of Godet et al. [2]. Within $24 \mathrm{~h}$, oxygenation improved to a similar proportion (i.e., doubling of the $\mathrm{PaO}_{2} / \mathrm{FiO}_{2}$ ratio). $\mathrm{PaCO}_{2}$ was kept normal, barotrauma never occurred, and no significant hemodynamic changes were observed during the course of HFPV treatment. Moreover, the respiratory and hemodynamic benefits were sustained for at least 6 days after initiation of HFPV. Interestingly, less improved oxygenation, longer ventilation and ICU dependency, and higher 30 -day mortality (50\% vs $18 \%$; $P=0.01$ ) were

\footnotetext{
*Correspondence: herbert.spapen@uzbrussel.be

${ }^{1}$ Intensive Care Department, University Hospital, Vrije Universiteit Brussel

(VUB), Laarbeeklaan 101, B-1090 Brussels, Belgium

Full list of author information is available at the end of the article
}

observed in pneumonia-related ARDS. Most deaths in the pneumonia group were related to intractable multiorgan failure. Whether HFPV adversely propagates reactive pathways in pneumonia-related ARDS that ignite remote inflammation and sustain organ damage remains unknown.

According to Godet et al. [2], HFPV perfectly fits within the "Open the Lung and Keep it Open" concept of protective lung ventilation in ARDS. Applying HFPV, however, differs considerably from a low tidal volume/ high positive end-expiratory pressure (PEEP) ventilation strategy where personalizing the PEEP level is primordial to minimize dynamic strain caused by alveolar recruitment/derecruitment [4]. Conventional HFPV settings may deliver injurious tidal volumes [5]. HFPV also significantly interferes with sedation protocols (e.g., lowlevel sedation, sedation breaks, etc.) and prone positioning, and requires supervision on a $24 / 7$ basis by a dedicated team of trained physicians and respiratory therapists. Our clinical experience with HFPV does not support current introduction of this technique for ventilating ARDS patients.

\section{Abbreviations \\ ARDS: Acute respiratory distress syndrome; HFPV: High-frequency percussive ventilation; PEEP: Positive end-expiratory pressure}

\section{Acknowledgements \\ Not applicable}

\section{Funding}

No funding

\section{Availability of data and materials}

Not applicable

\section{Authors' contributions}

HS and PMH designed the paper. HS, JDR, VVG, and PMH participated in drafting and reviewing. All authors read and approved the final version of the manuscript.

Ethics approval and consent to participate Not applicable 


\section{Consent for publication}

Not applicable.

\section{Competing interests}

The authors declare that they have no competing interests.

\section{Publisher's Note}

Springer Nature remains neutral with regard to jurisdictional claims in published maps and institutional affiliations.

\section{Author details}

'Intensive Care Department, University Hospital, Vrije Universiteit Brussel (VUB), Laarbeeklaan 101, B-1090 Brussels, Belgium. ${ }^{2}$ Intensive Care

Department, Centre Hospitalier Universitaire Brugmann, Brussels, Belgium.

Received: 31 January 2018 Accepted: 7 February 2018

Published online: 02 March 2018

\section{References}

1. Ferguson ND, Cook DJ, Guyatt GH, Mehta S, Hand L, Austin P, et al. Highfrequency oscillation in early acute respiratory distress syndrome. N Engl J Med. 2013;368(9):795-805. https://doi.org/10.1056/NEJMoa1215554.

2. Godet T, Jabaudon M, Blondonnet R, Tremblay A, Audard J, Rieu B, et al. High frequency percussive ventilation increases alveolar recruitment in early acute respiratory distress syndrome: an experimental, physiological and CT scan study. Crit Care. 2018;22(1):3. https://doi.org/10.1186/s13054-017-1924-6.

3. Spapen H, Borremans M, Diltoer M, Gorp W, Nguyen DN, Honoré PM. Highfrequency percussive ventilation in severe acute respiratory distress syndrome: a single center experience. J Anaesthesiol Clin Pharmacol. 2014; 30(1):65-70. https://doi.org/10.4103/0970-9185.125706.

4. Nieman GF, Satalin J, Andrews P, Aiash H, Habashi NM, Gatto LA. Personalizing mechanical ventilation according to physiologic parameters to stabilize alveoli and minimize ventilator induced lung injury (VILI). Intensive Care Med Exp. 2017;5(1):8. https://doi.org/10.1186/s40635-017-0121-x.

5. Allan PF. High-frequency percussive ventilation: pneumotachograph validation and tidal volume analysis. Respir Care. 2010;55(6):734-40. 